\section{Universidad, territorio y transformación social. Reflexiones en torno a procesos de aprendizaje en movimiento}

\author{
Elsegood, L y otros (2014). Avellaneda: \\ Undav Ediciones. 114 páginas. \\ Disponible en versión digital. \\ Reseñado por Luciana Fiorda \\ Universidad Nacional de Avellaneda \\ lucianafiorda@gmail.com
}

Este libro, que lleva su segunda edición en castellano y su primera edición al portugués a través de la UFP Editora, nos invita a reflexionar acerca de algunos caminos posibles para construir una universidad socialmente comprometida con base en una experiencia disruptiva e innovadora: la curricularización de la extensión a través del Trayecto Curricular Integrador Trabajo Social Comunitario, emprendido por la Universidad Nacional de Avellaneda desde su fundación.

Se rescata aquí el valor irremplazable de enseñar y aprender en contextos reales, situándonos en la tensión de resignificar los supuestos epistémicos que abrazan las experiencias territoriales como oportunidades concretas de distribución social del conocimiento. Las experiencias en comunidad ponen en debate el modelo ético y epistémico de ser universidad, y devienen insustituibles en la formación integral de los profesionales en tanto ciudadanos con sensibilidad y compromiso social, conscientes de su deber histórico para con la sociedad de la que forman parte. Universidad, territorio y transformación social. Reflexiones en torno a procesos de aprendizaje en movimiento es el primer libro en el marco de un proceso de construcción de un trayecto de enseñanza y aprendizaje que se va creando y recreando al mismo tiempo que la propia universidad. En este sentido, el libro exterioriza en términos teóricos qué es, qué se hace, para qué se lo hace, desde qué posición se está haciendo, cuáles son las condiciones de posibilidad que permiten lo que producimos, en qué modelo de universidad estamos pensando cuando desarrollamos el Trayecto Trabajo Social Comunitario, qué se entiende —en esta propuesta- por extensión universitaria y cómo se piensa la integración de la extensión a los planes de estudio de todos los estudiantes de la universidad. Este proceso de objetivación abre una grieta en el trabajo cotidiano que invita a sus protagonistas a repensar, resignificar, revisar todo aquello que vienen construyendo de modo sumamente vertiginoso.

La curricularización de la extensión universitaria se inscribe en una búsqueda pedagógica, política y epistemológica que tiene como desafío el integrar de forma estructural las experiencias e
Integración de la docencia y la extensión /

Reseña de libros

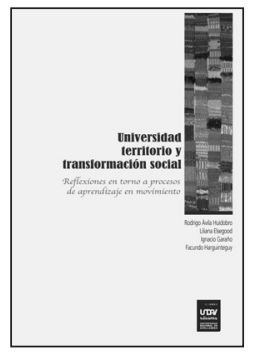

intereses de los sectores populares a los procesos de formación y producción de conocimiento, en un intento creativo, que permita nuevas prácticas y formas de hacer y rehacer la institución universitaria. Pero además, incorporar a los sectores populares y sus organizaciones a los procesos de enseñanza, aprendizaje y producción de conocimiento, resulta clave para poner en tensión saberes y herramientas metodológicas de la ciencia. Y justamente es la extensión universitaria entendida de modo bidireccional (y no como la función que irradia luz sobre el pueblo), la que tiene la potencialidad para problematizar el uso acrítico de dichas herramientas metodológicas y conceptuales.

Este Aprendizaje en Movimiento es una forma de acción sobre el mundo y es a partir de la acción que conocemos y que construimos teoría. Por todo esto, subrayamos que este involucramiento se realiza bajo el principio de que la universidad es un actor más del territorio, no desde la prepotencia o la superioridad de una ciencia vertical, elitista, ortodoxa que se vincula desde la colonización, la imposición o la sordera frente a las demandas y los procesos sociohistóricos en curso.

Este proceso iniciado en la Universidad Nacional de Avellaneda continúa su camino de construcción colectiva de conocimiento para que nazcan nuevos textos que puedan ser dichos y debatidos en el campo popular. 